\title{
Reflective Films and Expression of Light-regulated Genes in Field-grown Apple
}

\author{
Carole L. Bassett ${ }^{1}$ and D. Michael Glenn \\ USDA, Agricultural Research Service, Appalachian Fruit Research Station, 2217 Wiltshire Road, \\ Kearneysville, $W V 25430$
}

\begin{abstract}
ADDITIONAL INDEX wORDs. light perception, orchard management, photosynthesis, phytochrome, reverse transcriptionpolymerase chain reaction

Abstract. Reflective films are used in orchard management to improve fruit coloration. Numerous physiological studies on the effects of application of these films have been conducted, including variation of angles of light incidence and reflection, spectral determination of reflected light, and effects on photosynthesis and pigment development. At present there have been no studies on the effects of these treatments on gene expression, particularly with regard to genetic factors controlling light perception and genes targeted by specific regulators. We sampled a fully developed leaf from apple (Malus $\times$ domestica) branches of mature trees in $\mathbf{2}$ consecutive years. The grass between the tree rows was left untreated, sprayed with a formulation of a reflective particle film (RPF), or covered with a single layer of an aluminized plastic film (APF). Leaves at the same branch position were sampled between 1000 and $1200 \mathrm{HR}$ on sunny days. Nine different gene transcripts associated with light perception, sorbitol transport, and actin (control) were measured by semiquantitative reverse transcription-polymerase chain reaction and five by quantitative reverse transcription-polymerase chain reaction. Transcript abundance of most genes was unaffected by treatment or slightly enhanced by RPF. These results are consistent with earlier observations indicating that application of this film stimulated carbon partitioning to the fruit likely through the reduced red/far-red ratio of reflected light. In contrast, the level of several gene transcripts, including MdPif3, MdPhyB, and MdSot3, was reduced by application of the APF. Only one gene, MdElip1A/B, was significantly and dramatically elevated by APF.
\end{abstract}

Light perception in plants is critical to their survival because light regulates three important processes: skotomorphogenesis, photomorphogenesis, and photosynthesis. At ground level the composition of sunlight is $\approx 3 \%$ ultraviolet, $44 \%$ visible ( 380 to $780 \mathrm{~nm}$ ), and $53 \%$ infrared (Gueymard, 2004). Although sunlight is composed of all of these wavelengths (i.e., from 100 $\mathrm{nm}$ to $1 \mathrm{~mm}$ ), absorbance and reflectance by environmental factors can drastically influence the wavelengths impinging on the leaf surface. These factors include nearby plants and shading as well as soil surfaces, groundcovers, or both. In this study, our objective was to identify the effects of groundcovers reflecting different wavelengths of light on the expression of light-regulated genes in the leaves of field-grown apple. AbouKhaled et al. (1970) conducted the first systematic evaluation of reflective minerals as antitranspirants by applying a minimally processed kaolin mineral whitewash to bean (Phaseolus vulgaris), citrus (Citrus sinensis, Citrus limonimedica), and rubber (Ficus elastica) plants. Most of the radiation reflected from treated plants was in the visible range, and transpiration was reduced $20 \%$ to $25 \%$, primarily resulting from a reduction in heat load. However, some particle films applied to crops also reduced stomatal conductance $\left(g_{\mathrm{S}}\right)$, thus inhibiting photosynthesis (Moreshet et al., 1979; Stanhill et al., 1976). Recent research has focused on formulations that have a more beneficial effect on transpiration without reducing photosynthesis.

Received for publication 3 Mar. 2014. Accepted for publication 5 May 2014. We thank Sharon Jones and Jing Ma for their expert assistance in sampling, preparing RNA, and conducting the gene expression analyses.

Mention of a trademark, proprietary product, or vendor does not constitute a guarantee or warranty of the product by the U.S. Department of Agriculture and does not imply its approval to the exclusion of other products or vendors that also may be suitable.

${ }^{1}$ Corresponding author. E-mail: Carole.Bassett@ars.usda.gov.
Glenn et al. $(2001,2003)$ demonstrated that $g_{\mathrm{S}}$, transpiration, and photosynthesis were increased with the application of both hydrophobic and hydrophilic particle films that were based on calcined kaolin. Particle films on whole trees can also increase reflection of ultraviolet-A and ultraviolet-B radiation from the plant surface without a reduction in gas exchange and minimal reduction in photosynthetically active radiation $(P A R)$ interception. Particle film technology is considered appropriate to organic agriculture to control insects and diseases and has been successfully applied to fruit and nut orchards as well as vegetable crops.

Particle films and reflective surfaces have also been used to improve fruit quality (Glenn and Puterka, 2007; Layne et al., 2001, 2002; Miller and Greene, 2003). In studies with 'Empire' apple, Glenn and Puterka (2007) measured increased PAR levels in tree canopies treated with either a reflective particle film or an aluminized plastic film on the groundcover/driveway between the trees. The red-far red ratio (R/FR) reflected from the RPF was higher than the untreated control or the APF treatment; the APF treatment approximated the R/FR of full sun.

Perception of light by plants is regulated by four different classes of photoreceptors, so far identified as phytochromes, cryptochromes, phototropins, and Zeitlupes. In the model plant, Arabidopsis thaliana, five genes encode the phytochrome receptor family $(P h y A-E)$, two encode the cryptochrome family (CRY1 and CRY2), two encode the phototropin family (Phot1 and Phot2), and three (ZTL, FKF1, and LKP2) encode the Zeitlupe family (Kim et al., 2007). Recently, strong supporting evidence for the $\beta$-propeller protein, UVR8, as the ultraviolet-B photoreceptor has been presented (Rizzini et al., 2011).

In established light-grown plants, PHYB predominates and, in contrast to what is observed in etiolated seedlings, is already located in the nucleus (Kircher et al., 2002). Phytochrome B and, to a lesser extent, phytochromes D and E are primarily 
responsible for the shade avoidance syndrome. Phytochrome interacting factors 3 through 5 (PIFs3-5) mediate this response (Supplemental Fig. 1). In addition, the phytochrome interactinglike factor gene, PIL1, is rapidly activated by exposure to low $\mathrm{R} /$ FR light (Salter et al., 2003), and this response can be maintained under long periods of FR exposure (Roig-Villanova et al., 2006).

Blue light and ultraviolet-A responses are perceived by a variety of receptors. Cryptochromes are flavin-containing proteins similar in sequence to the DNA repair photolyases (Chaves et al., 2011); they perceive both blue light and ultraviolet-A wavelengths. Phototropins are serine/threonine receptor kinases that phosphorylate a variety of proteins (Tokutomi et al., 2008). All of the light receptors are modulated or influenced by the Zeitlupe family of receptors controlling circadian rhythms.

One of the central components of light signaling is the leucine zipper transcription factor, HY5 [elongated hypocotyl 5 (Supplemental Fig. 1)]. Transcription of $H y 5$ is influenced by all of the different light receptor types, including the UVR8 protein (Brown et al., 2005), CRY1 (Vandenbussche et al., 2007), and phytochromes/PIFs. HY5 has over 3000 downstream targets, including genes associated with photosynthesis, photomorphogenesis, or, in some cases, stress response (Lee et al., 2007). Among them are genes encoding the small subunit of Rubisco $(R b c S)$, which represents the key step in carbon fixation and various chlorophyll $a / b$ binding proteins, which are essential for the light reactions of photosynthesis. In addition, early light-induced protein (Elip) genes encoding proteins similar to chlorophyll $a / b$ binding proteins are also targets of HY5 and are believed to protect developing seedlings from environmental stresses such as photo-oxidation (Hutin et al., 2003) and heat shock (Harari-Steinberg et al., 2001).

Most studies of light perception and transduction at the molecular level have been conducted on etiolated seedlings of herbaceous plants, and little is known about light signaling in mature, field-grown woody plants. Furthermore, many orchard management protocols directly affect tree light perception. For example, opening up the canopy of fruit trees to increase light exposure to the internal portion of the canopy is a common management practice among many types of fruit trees (Marini and Barden, 1987). Ground covers, row and tree spacing as well as materials sprayed on or around the trees can also have an effect on light reaching the canopy. The ultimate goal of horticultural molecular biology is to transfer information derived from studies of genes and gene products to useful field applications for the maintenance/improvement of productivity. The objective of the current study was to measure the effects on expression of genes associated with different aspects of light perception and transduction in apple leaves exposed to two groundcover treatments that increase canopy light levels but with different light quality. Based on light wavelengths reflected by the treatments, genes representing different aspects of the phytochrome light induction pathway were chosen to represent events ranging from perception to transduction to activation of light-responsive targets. In addition, the sorbitol transporter was included as a representative gene involved in carbon allocation, and actin served as a lightinsensitive control.

\section{Materials and Methods}

Collection of Plant MATERIAL. Trees of Malus $\times$ domestica 'Empire'/'M.7A' (M.7A) were used in this study. The apple orchard was planted at Kearneysville, WV (lat. $39.3^{\circ} \mathrm{N}$, long. $\left.77.9^{\circ} \mathrm{W}\right)$ in 1992 in a north-south orientation in a moderate density configuration $(500$ trees/ha at $6.0 \times 3.3-\mathrm{m}$ spacing $)$. The trees were not irrigated and were sprayed with conventional pesticides. A separate group of trees was used in each year (2005 and 2006). The experimental design and treatments were established in 2002 as described previously (Glenn and Puterka, 2007). The focus of the current study was on reflective materials [i.e., aluminized film strips (Clarke Ag Plastics, Greenwood, VA)] and a reflective particle formulation [95\% rain-resistant calcined kaolin (Engelhard Corp., Iselin, NJ)], that were designated as APF and RPF treatments in Glenn and Puterka (2007), respectively.

Leaves were collected from branches at the outer portion of the canopy on the east side of the tree at working height $(\approx 2 \mathrm{~m})$. The approximate 12th leaf from the shoot apex was sampled from four branches that were 18 to $22 \mathrm{~cm}$ long. Four leaves from each of six replicated trees were collected, pooled, rinsed with deionized water, and immediately placed in liquid $\mathrm{N}_{2}$. Leaves were stored at $-80{ }^{\circ} \mathrm{C}$ until used for RNA extraction. Leaves at the 12 th position were nearing full expansion on the collection dates and considered to be fully photosynthetically active. Samples were taken in early Aug. 2005 (six replicates, one tree/replicate) and in late July 2006 (six replicates, two trees/replicate) between 1000 and 1200 HR Eastern Daylight Time under full sunlight. The statistical design was based on the field study design of a randomized complete block with six replications.

IDENTIFICATION OF APPLE GENES EQUIVALENT TO $A$. THALIANA GENES. Apple expressed sequence tags (ESTs) for select genes when available were downloaded from GenBank [National Center for Biotechnology Information (NCBI)] translated and aligned with the contig assembly program [CAP3 (Huang and Madan, 1999)] to potential $A$. thaliana homologs. Where no EST was available, the $A$. thaliana protein sequence was used to search the apple genome (Velasco et al., 2010) for the closest sequence match. The cognate nucleic acid sequence was in turn used in a BLASTn (basic local alignment search tool, NCBI) search against the apple genome, and the derived polypeptides from the resulting sequence(s) were aligned with $A$. thaliana sequences using COBALT (NCBI). The alignment results are shown in Supplemental Table 1. MdSot3 [apple sorbitol transporter (GenBank accession no. AB125646)] and genes obtained from the alignments were used to design primers for the semiquantitative reverse transcription-polymerase chain reaction and quantitative reverse transcription-polymerase chain reactions using Primer 3 (Rozen and Skaletsky, 1998) and Primer 3Plus software (Untergasser et al., 2007).

EXPRESSION ANALYSIS BY SEMIQUANTITATIVE RT-PCR. Leaves from individual trees were ground in liquid $\mathrm{N}_{2}$, and total RNA was extracted according to the manufacturer's protocol using a Concert Plant RNA Reagent kit (Invitrogen, Carlsbad, CA). Total RNA was treated with DNase (RNA Clean and Concentrator-25; Zymo Research, Irvine, CA). The treated RNA was assayed for chromosomal DNA contamination using primers for the subunit7 gene of the peach (Prunus persica) 26S proteosome (GenBank accession no. AF041258), a highly conserved component of the common protein-degradation pathway. Equal amounts of DNA-free total RNA from the pooled leaf samples were converted to cDNA using SuperScript III according to the manufacturer's directions (Invitrogen). One microliter of each cDNA was separated 
on $1.8 \%$ agarose gels, stained with SYBR ${ }^{\circledR}$ Gold (Life Technologies, Applied Biosystems, Grand Island, NY), and the image scanned on a STORM or TYPHOON Image Analyzer (GE Healthcare, Piscataway, NJ). Scanned images were analyzed with ImageQuant TL Version 7 software (GE Healthcare) to determine the relative quantity of each cDNA (Madlung et al., 2002). These were subsequently adjusted by dilution so that equal amounts of the cDNAs served as templates in the polymerase chain reaction (PCR) reactions.

The annealing temperatures of the PCR reactions were optimized for each primer set against 'Empire' apple genomic DNA. Primers used in this study are listed in Supplemental Table 2 and were verified by sequencing amplicons generated from genomic DNA templates. PCR reactions used HotStarTaq plus Master Mix (Qiagen, Valencia, CA) and an equal volume of water $+0.2 \mathrm{uL}$ each primer $(100 \mu \mathrm{M})$. Cycling conditions were $95^{\circ} \mathrm{C}$ for $5 \mathrm{~min}$ followed by 35 cycles of $1 \mathrm{~min}$ at $95^{\circ} \mathrm{C}$, $1 \mathrm{~min}$ at the primer optimal annealing temperature $\left(55\right.$ to $\left.60^{\circ} \mathrm{C}\right)$, and $1.5 \mathrm{~min}$ at $72^{\circ} \mathrm{C}$. At the end of the 35 cycles, the reaction was kept at $72{ }^{\circ} \mathrm{C}$ for $10 \mathrm{~min}$ to complete product extension. cDNA templates that appeared saturated under these cycling conditions were diluted to a concentration designed to yield approximately equal product intensities similar to the less abundant genes and rerun. MdAct, encoding an apple actin gene, served as a control based on a previous study indicating that it does not respond to light (Lu et al., 2002) and to our results indicating that it did not differ by treatment.

Products of each reaction were separated on $1 \%(\mathrm{w} / \mathrm{v})$ agarose gels in TAE (40 mM Tris acetate, $\mathrm{pH} 8,1 \mathrm{~mm}$ ethylenediamine tetraacetic acid) buffer and stained by incubation for $20 \mathrm{~min}$ with SYBR ${ }^{\circledR}$ Gold $(10,000 \times)$ (Life Technologies) diluted 1:30000 with deionized water. Images were captured and analyzed as before. Analysis of bands included total area and intensity. The data were subjected to statistical analysis using the Ryan-Einot-Gabriel-Welsch multiple range test, proc GLM (SAS Version 9.2; SAS Institute, Cary, NC).

Expression ANALYSIS BY QUANTITATIVE RT-PCR. RNA extracted and purified as described previously was used as a template in quantitative reverse transcription-polymerase chain reactions (qRT-PCRs). Primers for qRT-PCR were designed with Primer 3 Plus software and tested against genomic DNA for amplicon quality. Each primer pair was used to prime qRT-PCRs to quantify transcript accumulation in leaves from trees whose groundcover was treated as described previously. The qRT-PCRs were conducted in a 7900HT Fast Real-Time PCR System (Life Technologies) using the Platinum $^{\circledR}$ SYBR $^{\circledR}$ Green qPCR SuperMix-UDG (Uracil-DNA Glycosylase) with ROX (reference dye) kit from Life Technologies, and the reaction parameters were as follows: $48^{\circ} \mathrm{C}$ for $30 \mathrm{~min}, 95^{\circ} \mathrm{C}$ for $5 \mathrm{~min}$ followed by 40 cycles of $95^{\circ} \mathrm{C}$ for $15 \mathrm{~s}$ and $56^{\circ} \mathrm{C}$ for $1 \mathrm{~min}$ (annealing) and a final disassociation step consisting of $95^{\circ} \mathrm{C}$ for $15 \mathrm{~s}, 60^{\circ} \mathrm{C}$ for $15 \mathrm{~s}$, and $95^{\circ} \mathrm{C}$ for $15 \mathrm{~s}$. Actin served as an internal control for the qRT-PCR experiments (Lu et al., 2002). In addition, prior testing of cDNAs from all three treatments revealed that Cot (concentration $\times$ time) values were not significantly different for MdAct. The relative standard curve method was used to analyze the data, and the results were subjected to statistical analysis using the RyanEinot-Gabriel-Welsch multiple range test. In addition, simple linear correlations were calculated across treatments and years for all genes $(r>0.273$ for $P=0.05)$ measured by semiquantitative RT-PCR and qRT-PCR methodology.

\section{Results}

To follow the potential effects of reflective film treatment on expression of light-responsive genes, we selected genes representative of different light spectral responses, as well as those associated with different steps in the light signaling pathways (Supplemental Fig. 1). These genes encoded apple genes related to $A$. thaliana phytochromes B and E (MdPhyB, MdPhyE), long hypocotyl 5 (MdHy5), phytochrome interacting factor 3 (MdPif3), MdRbcS (small subunit of ribulose bis-phosphate carboxylase), MdLhcb2-2 (light harvesting complex 2, type 2 chlorophyll $a / b$ binding protein gene), MdSot3 (sorbitol transporter; Watari et al., 2004), and MdElip1A/B and MdElip1D.

Identification of apple genes equivalent to $A$. thaliana genes used apple ESTs ['Royal Gala', (Wisniewski et al., 2008) and 'Goldrush' (S. Korban, NCBI EST database)] where available. If no ESTs were present in the gene bank databases, we used $A$. thaliana sequences to search the apple genome (Sanzol, 2010; Velasco et al., 2010). Apple sequences with significant E values $\left(<1 \times 10^{-8}\right)$ were used to search the genome a second time. All candidate genes were translated and aligned to the $A$. thaliana sequences. The apple sequence with the best alignment score using COBALT (NCBI) and BLASTp was chosen as the putative apple equivalent (Supplemental Table 1). Primers for semiquantitative and qRT-PCR were designed from these templates (Supplemental Table 2).

All cDNAs from leaves of mature trees were first assessed by semiquantitative RT-PCR using primers for genes with known responses to light. MdAct was tested as a "constitutive" control to monitor variation in gel loading, dilution series, and expression under field conditions. In 2005 only transcript accumulation of MdElip1D and MdSot3 was significantly different from controls by semiquantitative RT-PCR analysis, being highest in leaves sampled from RPF-treated trees (Table 1). Levels of MdElip 1D were not significantly different in 2006 (Fig. 1A);

Table 1. Summary of light-regulated gene responses in 'Empire' apple leaves to different groundcover treatments in 2005 and 2006 using two assay methods.

\begin{tabular}{|c|c|c|c|c|c|c|c|c|}
\hline \multirow[b]{4}{*}{ Gene } & Sem & uantite & Ive RT & $\mathrm{PCR}^{\mathrm{z}}$ & Qua & atitativ & e RT- & PCR \\
\hline & \multicolumn{8}{|c|}{ Treatment } \\
\hline & \multicolumn{2}{|c|}{$\mathrm{RPF}^{\mathrm{z}}$} & \multicolumn{2}{|c|}{$\mathrm{APF}^{\mathrm{z}}$} & \multicolumn{2}{|c|}{ RPF } & \multicolumn{2}{|c|}{ APF } \\
\hline & 2005 & 2006 & 2005 & 2006 & 2005 & 2006 & 2005 & 2006 \\
\hline$\overline{M d A c t}$ & $0^{\mathrm{y}}$ & 0 & 0 & 0 & 0 & 0 & 0 & 0 \\
\hline$M d P h y B$ & 0 & + & 0 & 0 & & & & \\
\hline$M d P h y E$ & 0 & & 0 & & & & & \\
\hline MdHy5 & 0 & 0 & 0 & 0 & 0 & 0 & 0 & 0 \\
\hline MdPif3 & 0 & + & 0 & - & 0 & 0 & 0 & 0 \\
\hline MdLhcb2-2 & 0 & 0 & 0 & 0 & & & & \\
\hline$M d R b c S$ & 0 & 0 & 0 & - & & & & \\
\hline MdElip $1 A / B$ & 0 & + & 0 & + & 0 & 0 & 0 & ++ \\
\hline MdElip $1 D$ & + & 0 & 0 & 0 & 0 & 0 & + & 0 \\
\hline MdSot3 & + & + & - & - & & & & \\
\hline
\end{tabular}

${ }^{\mathrm{z}} \mathrm{RT}-\mathrm{PCR}=$ reverse transcription - polymerase chain reaction; $\mathrm{RPF}=$ reflective particle film (Engelhard Corp., Iselin, NJ); APF = aluminized plastic film (Clarke Ag Plastics, Greenwood, VA).

${ }^{y}$ Significant differences are indicated by symbols + and $-:+=$ significantly increased over control, $++=$ greater than 10 times increased over control; - = significantly decreased relative to control; 0 no significant difference compared with control; blank cell $=$ not done. 
however, MdSot 3 transcript abundance was significantly different from the control, being highest under RPF treatment and lowest under APF (Fig. 1B). In 2006, like in 2005, MdAct, $M d L h c b 2-2$, and MdHy5 continued to show no difference in expression by treatment. In contrast to the 2005 results, expression of MdPif3, MdPhyB, and MdElip1A/B was highest in the 2006 RPF-treatment; in fact, the APF treatment clearly suppressed $M d R b c S$ (Fig. 1C) and MdPif3 (Fig. 1B) transcript abundance as it did in both years for MdSot 3 transcripts.

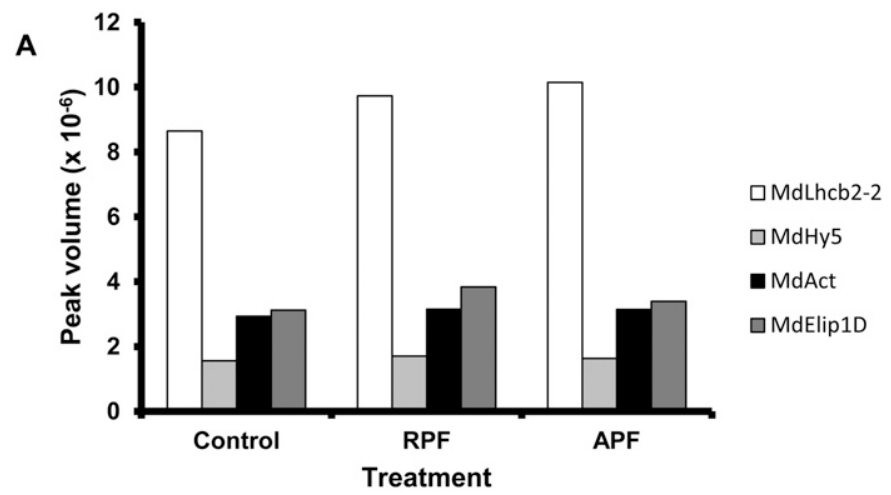

B

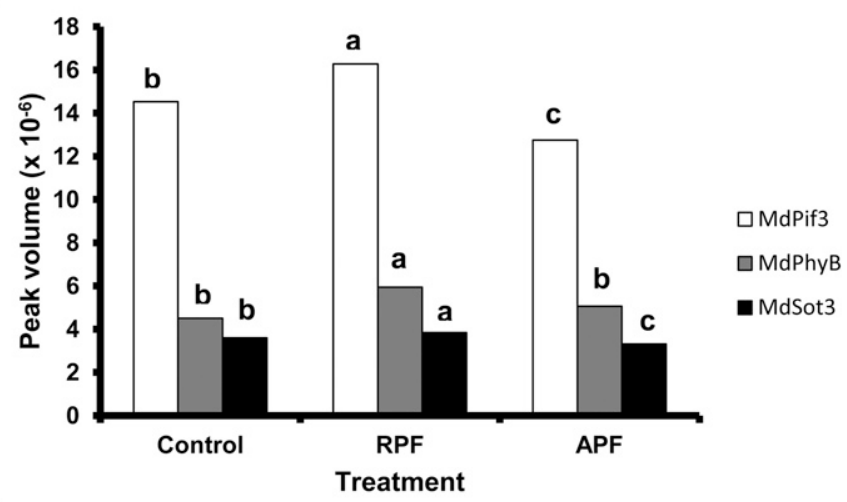

C

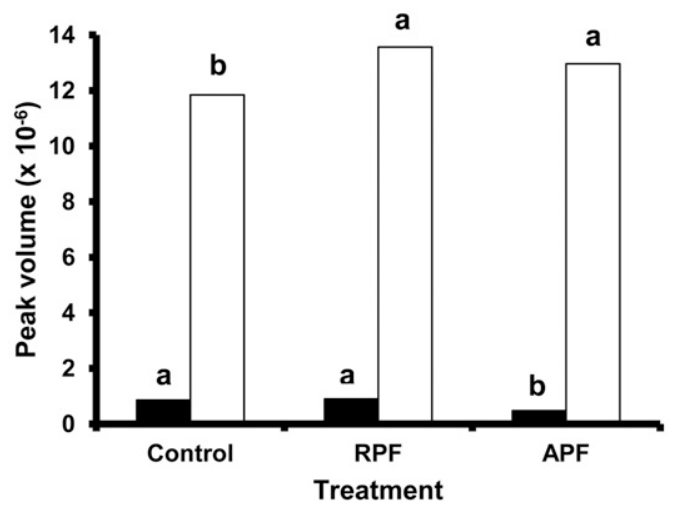

MdRbcS

$\square$ MdElip1A/B

Fig. 1. Semiquantitative expression of light-regulated 'Empire' apple leaf cDNAs from trees treated with different manufactured groundcovers. Leaves were collected and processed as described in "Materials and Methods." The cDNAs generated were diluted to insure equal concentrations in each reaction. Amplification products were scanned in a STORM/TYPHOON image analyzer using ImageQuant software (GE Healthcare, Piscataway, NJ) to quantify the bands. (A) Graph of genes with no significant difference in expression by treatment compared with control; (B) graph of genes showing highest levels of expression under reflective particle film (RPF) treatment; (C) graph of genes with opposite patterns of expression by treatment. Columns with the same letter are not significantly different at $P=0.05$; control $=$ untreated grass controls; APF $=$ aluminized plastic film.
Semiquantitative RT-PCR was sufficiently reproducible to evaluate transcript accumulation of MdAct, MdHy5, MdLhcb22, and MdSot3 in 2005-06 (compare Table 1 and Fig. 1A-B). However, the variability of results using this technique with respect to the abundance of MdPif3, MdElip1A/B, and $M d E$ lip $1 D$ mRNAs led us to analyze their expression using the more accurate qRT-PCR methodology with actin serving as an internal normalization control and $M d H y 5$ expression as a lightresponsive control, because their abundance was unaffected by treatment [Table 1; Fig. 1A (semiquantitative RT-PCR)]. Quantitative RT-PCR analysis of MdPif3 and MdHy5 for years 200506 (Table 1; Fig. 2) was similar, revealing no differences between treatments and controls. Expression of MdElip1A/B (in 2005) and MdElip1D (in 2006) was also not significantly different by treatment. On the other hand, expression of MdElip1D was elevated by APF in 2005 but not in 2006; in contrast, Elip $1 A / B$ showed a dramatic increase in transcript abundance in response to the APF treatment in 2006, but not in 2005.

Correlation of expression by semiquantitative RT-PCR of the apple genes used in this study provided a dimension of relatedness among genes. Expression of MdLhcb2-2 and $M d S o t 3$ was significantly correlated with expression of the apple PhyB, Hy5 and the Elip genes (Tables 2 and 3). Interestingly, $M d R b c S$ expression only correlated with $M d A c t$ and MdPif3 expression. Analysis of expression of the genes determined by qRT-PCR indicated that the MdElip genes were correlated with each other and were the only correlation detected.

\section{Discussion}

Most studies of light perception and the regulation of lightactivated genes have focused on young, herbaceous plants, and very little information is available regarding studies in woody species. Even less is known about how these genes respond to

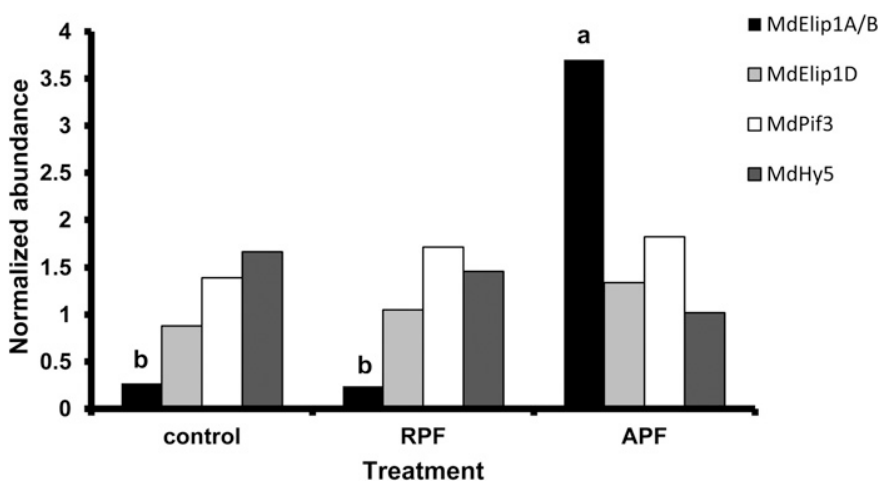

Fig. 2. Quantitative expression of light-regulated 'Empire' apple leaf cDNAs from trees treated with different manufactured groundcovers. Leaves were collected and processed as described in "Materials and Methods." Equal amounts of total RNA were used as template in reactions using the SYBR One-step Supermix with ROX quantitative reverse transcription-polymerase chain reaction kit following the manufacturer's instructions (Life Technologies, Grand Island, NY). Graph of two transcription factors with central roles in light signaling (MdHy5 and MdPif3) and two genes associated with high light/ultraviolet stress (MdElip $1 A / B$ and $D$ ). Transcript abundance was normalized to the apple actin transcript. Columns with the same letter are not significantly different $($ MdElip $1 A / B)$; columns without letters are not significantly different at the $P=0.05$ level; RPF $=$ reflective particle film; $\mathrm{APF}=$ aluminized plastic film. 
Table 2. Summary of correlations between 'Empire' apple light-responsive gene expression over the 2005 and 2006 semiquantitative reverse transcription-polymerase chain reaction results.

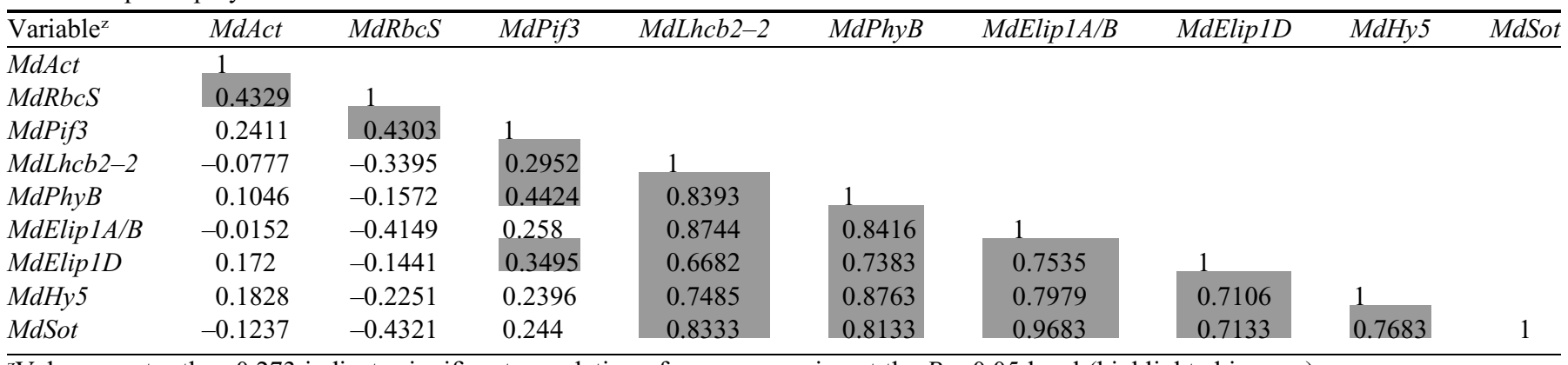

${ }^{\mathrm{z}}$ Values greater than 0.273 indicate significant correlation of gene expression at the $P=0.05$ level (highlighted in gray).

Table 3. Summary of correlations between 'Empire' apple lightresponsive gene expression over the 2005 and 2006 quantitative reverse transcription-polymerase chain reaction results.

\begin{tabular}{lccccc}
\hline Variable $^{\mathrm{z}}$ & MdHy5 & MdElip1A/B & MdElip1D & MdPif3 & MdAct \\
\hline MdHy5 & 1 & & & & \\
MdElip1A/B & -0.1126 & 1 & & & \\
MdElip1D & -0.0516 & 0.3971 & 1 & & \\
MdPif3 & -0.0672 & 0.0169 & -0.3825 & 1 & \\
MdAct & 0.2435 & -0.1171 & 0.0819 & -0.4742 & 1
\end{tabular}

${ }^{\mathrm{z}}$ Values greater than 0.273 indicate significant correlation of expression at the $P=0.05$ level (highlighted in gray).

light regulation in the field where many different environmental factors can modulate their expression. Previous studies of apple trees treated with particle films as groundcovers or groundcover supplements have shown beneficial effects on fruit color and fruit size (Glenn and Puterka, 2007), but little or no information is available as to how these treatments affect light transduction in leaves at the molecular level. Because leaves are the primary "source" organs that ultimately affect fruit size, it is important to understand how the expression of light-regulated genes in leaves is affected by different groundcover treatments used under field conditions. Such studies will be useful in the future for designing strategies for improvement of agricultural production systems, particularly with regard to maintenance of orchard productivity.

The following genes whether analyzed by semiquantitative RT-PCR or qRT-PCR showed few, if any, differences by treatment or year compared with untreated controls: MdAct, MdPhy $B$ (and MdPhyE), MdHy5, MdPif3, MdLhcb2-2, and $M d R b c S$. The lack of response regarding MdAct expression is consistent with previous studies indicating that this gene does not respond appreciably to light (Lu et al., 2002). Most of the studies conducted on the phytochromes and interacting factors and on key transcription regulatory proteins have centered on herbaceous plants, yet it is likely that these genes would behave somewhat differently in woody species. For example, in $A$. thaliana, PhyA transcripts are regulated diurnally under short days, but not in plants grown under long days (Mockler et al., 2003). In contrast, in field-grown grape (Vitis vinifera), both $P h y A$ and $B$ were controlled by a diurnal rhythm under long days (December, long days $=14$ h 40 min light in the southern hemisphere) but were uniformly at maximum abundance under short days (April, short days = 11 h 12 min light) (Kühn et al., 2009). Although our experiments were conducted in June and July (long days) where, like grape, both apple phytochromes could have been oscillating, this is probably not a contributing factor to the field variation we observed, because collection times were always in full sun at the same time of day.

It is well known that phytochromes are predominantly regulated at the post-translational level, existing in two forms and intracellular locations, depending on the ratio between $\mathrm{R}$ and FR light (Kircher et al., 1999; Sakamoto and Nagatani, 1996). Therefore, the lack of effect on transcript accumulation resulting from reflective particle treatment in our study may be more pronounced at the protein level or in the receptor's ability to translocate between the cytoplasm and nucleus given that the $\mathrm{R} / \mathrm{FR}$ of RPF reflected light $(0.53)$ is considerably different from that of the APF (1.0) groundcover.

Both HY5 and PIF3 are transcription factors that are part of a light-regulated cascade. The expression of Hy5 in A. thaliana is regulated directly or indirectly by PhyA and B (Koornneef et al., 1980; Oyama et al., 1997) by UVR8, the photoreceptor of ultraviolet-B light (Brown et al., 2005; Ulm et al., 2004) and by CRY1 (Liu et al., 2011). The fact that MdHy5 expression was not significantly different by treatment in either sampling year is somewhat surprising because $H y 5$ is induced by narrow band ultraviolet-B, which is almost completely reflected by APF [81\% of PAR (D.M. Glenn, unpublished data)]. Ultraviolet-B exposure is divided into two stages: a narrowband, very rapid (minutes) photomorphogenic effect and a broadband slower stress response (Favory et al., 2009; Ulm et al., 2004). In $A$. thaliana, AtHy5 transcript levels rise quickly (within $2 \mathrm{~h}$ of dawn) in natural light (Sellaro et al., 2011). However, because our sampling times were well after dawn, MdHy5 levels were likely at maximum and would probably have shown little difference in response to the two treatments.

PIF3 is a transcription factor involved in both photomorphogenesis and shade avoidance (Supplemental Fig. 2). MdPif3 levels were not different by treatment using qRT-PCR analysis in either 2005 or 2006. The lack of treatment differences in MdPif3 transcripts is consistent with the expression of MdHy5 and may reflect the functional relationship between the two transcription factors.

Lhcb2-2 and $R b c S$ are downstream targets of light regulation associated with the light reaction of photosynthesis and carbon fixation, respectively. The expression of both genes in apple leaves in 2005 was unaffected by treatment. In 2006, both genes were elevated by APF treatment; however, only $M d R b c S$ expression differences were significant, although small.

Reflection from the mylar film increases the $\mathrm{R} / \mathrm{FR}$ ratio impinging on much of the leaf canopy undersurface to a ratio 
close to that of sunlight (1.1 vs. 1.35) compared with leaf undersurfaces above the untreated grass control (0.33). Although weather patterns for the sampling times in 2005 and 2006 were similar, as was the PAR measured at the time of sampling, it is possible that cloudy days before sampling in 2005 vs. 2006 lowered the APF R/FR ratio and suppressed its cumulative effect.

At least four different Elip genes (designated MdElip 1A$1 D$ ) reside on the apple genome. Semiquantitative primer pairs, MdELIPF2 and R2-3, and qPCR primers, qMdELIP2F2 and R2, would not amplify MdElip1C or MdElip1D under the conditions used but would amplify both MdElip $1 A$ and $1 B$ (Supplemental Table 2). On the other hand, primer pairs MdELIPF1 and R1, as well as qMdELIP1F2 and R2, would selectively amplify MdElip1D.

MdElip1D expression was most consistent in 2006 where no difference by treatment was observed. In 2005 significant differences were determined but they were not consistent by treatment or by method. MdElip $1 A / B$ expression was not significantly different by treatment in 2005 but was increased by APF in 2006 nearly 14 times over the control by qRT-PCR analysis. Interestingly, expression of both MdElip $1 A / B$ and $D$ correlated with each other in both semiquantitative and quantitative analyses. In contrast, although Elip genes are targets of Hy5, neither correlated with this transcription factor. This suggests that APF reflective film (higher ultraviolet reflection) may have uncoupled the normal interaction between HY5 and the Elip1 promoters, although this seems unlikely because both Hy5 and Elipl are increased in A. thaliana shortly after ultraviolet treatment (Ulm et al., 2004). Another possibility is that APF triggers Elipl induction through a HY5-independent pathway. This seems more likely because, as noted previously, Elip $1 A / B$ may be subject to heat shock induction, and films like APF can add as much as $2{ }^{\circ} \mathrm{C}$ to the air temperature in their immediate environment (Layne et al., 2001).

The promoters of both MdElip1A and $B$ genes are very similar, having several elements related to light regulation (Supplemental Fig. 3). Both genes also have a long repeat element upstream of the consensus TATA box. MdElip1A has two Pif3 response elements, whereas Elip1B has none. MdElip 1B has an upstream consensus TATA element close to an osmoregulatory element, both of which are absent from the MdElip1A promoter. Heat shock elements in both promoters are located much further upstream than the sequence shown in Supplemental Figure 3. Along these same lines, the promoter of MdElip1D (not shown), although lacking in heat shock response elements within the first 1500 bases upstream of the ATG translation start codon, possesses 10 ACGT cores, elements related to both light and hormone responses that could indicate potential regulation by other types of abiotic stress.

ELIPs are associated with a number of abiotic stress-responsive pathways. In $A$. thaliana, R, FR, blue, and ultraviolet-A light positively regulate AtElipl and 2 expression (Adamska et al., 1992; Harari-Steinberg et al., 2001), and this regulation seems to be independent of light intensity with respect to $\mathrm{R}$ and blue light (Adamska, 1995). Although only AtElipl induction is promoted by HY5 in light, heat shock induction of both AtElip1 and 2 is independent of both light and HY5 activity (Harari-Steinberg et al., 2001).

Another interesting observation was reported by Mishra et al. (2012) in A. thaliana. AtELIP proteins 1 and 2 were only expressed in field-grown plants, not in plants grown in controlled chambers under different light regimes. The highest light intensity used on growth chamber-grown plants was $600 \mu \mathrm{mol} \cdot \mathrm{m}^{-2} \cdot \mathrm{s}^{-1}$ quanta, whereas the leaves of field-grown plants were harvested at noon in full sunlight $\left(\approx 1900 \mu \mathrm{mol} \cdot \mathrm{m}^{-2} \cdot \mathrm{s}^{-1}\right.$ quanta at the latitude indicated). This result indicates that the high light intensity and ultraviolet content of full sunlight can induce these photoprotective proteins.

Sorbitol is the primary transport sugar in apple. It is synthesized in leaves (source) and transported to other tissues (sink) as required. Multiple sequences corresponding to the apple sorbitol transporter were found in the apple genome. However, the primer pair used to assay expression would have only recognized MdSot3 (Watari et al., 2004). This gene was selected on the assumption that it would show little or no light regulation. Surprisingly, MdSot3 abundance was increased by RPF treatment but decreased by APF. Both changes were statistically significant in both years and may reflect differences in ultraviolet-B wavelengths reflected by the two materials or $\mathrm{R} / \mathrm{FR}$ effects on sorbitol translocation. Expression of MdSot3 by semiquantitative RT-PCR correlated with $\mathrm{Hy} 5$ transcript abundance but not with Pif3; this is consistent with the role of HY5 in activation of downstream genes. Glenn and Puterka (2007) found that RPF increased fruit size in all years in contrast with APF and hypothesized that the reduced R/FR reflection increased carbon transport to fruit as was demonstrated by others (Fortnum and Kasperbauer, 1992; Kasperbauer, 1987, 2000; Kasperbauer and Hunt, 1998; Kasperbauer and Karlen, 1986; Matheny et al., 1992). Their interpretation is supported by the consistent upregulation of the sucrose transporter gene MdSot3 (Table 1).

Despite some year-to-year differences in response to treatment, several general conclusions can be drawn. Most of the genes analyzed in this study were either unchanged by the groundcover treatments or were elevated (e.g., MdSot3, $M d P i f 3$, and $M d P h y B$ ) by a reflective particle film applied to the groundcover. The aluminized plastic film suppressed expression of MdPif3, MdRbcS, and MdSot3. However, APF treatment evoked the strongest positive response on MdElip $1 A / B$ expression. We conclude that treatment with RPF was either stimulatory or not different from untreated controls regarding the expression of genes associated with light regulation. In contrast, the expression of several light-responsive genes was decreased by APF treatment with the exception of the early light-induced protein, MdElip $1 A / B$, which was significantly stimulated by APF treatment. These results parallel the field study of Glenn and Puterka (2007) regarding the separation of gene responses; i.e., RPF significantly increased fruit size and also increased MdSot 3 expression. Increased sorbitol transport is likely related to increased carbon partitioning to the fruit. The increase in MdPif3 and $M d P h y B$ in leaves may be a consequence of the altered R/FR ratio of the RPF light quality, which is associated with modest improvement in fruit color. Conversely, APF significantly increased fruit color (Glenn and Puterka, 2007) and MdElip 1A/B in our study, both observations of which are primarily ultraviolet-B light-dependent responses. Ultraviolet-B improvement in fruit color is likely the result of enhanced transcription of pigment synthesis genes for protection, similar to the MdElip $1 A / B$ response, which is also associated with protection against ultraviolet and high lightintensity damage. This study illustrates that gene expression can be tied to field responses and used to identify critical pathways influenced by cultural practices. It is speculated that further experimentation to refine the results presented here 
could lead to the development of strategies to exploit light stress (e.g., ultraviolet, high light intensity, and modifying R/FR) to improve the quality or effectiveness of tree fruit production systems (e.g., see Wargent and Jordan, 2013).

\section{Literature Cited}

Abou-Khaled, A., R.M. Hagan, and D.C. Davenport. 1970. Effects of kaolinite as a reflective antitranspirant on leaf temperature, transpiration, photosynthesis and water-use efficiency. Water Resour. Res. 6:280-289.

Adamska, I. 1995. Regulation of early light-inducible protein gene expression by blue and red light in etiolated seedlings involves nuclear and plastid factors. Plant Physiol. 107:1167-1175.

Adamska, I., K. Kloppstech, and I. Ohad. 1992. UV light stress induces the synthesis of the early light-inducible protein and prevents its degradation. J. Biol. Chem. 267:24732-24737.

Brown, B.A., C. Cloix, G.H. Jian, E. Kaiserli, P. Herzyk, D.J. Kliebenstein, and G.I. Jenkins. 2005. A UV-B-specific signaling component orchestrates plant UV protection. Proc. Natl. Acad. Sci. USA 102:18225-18230.

Chaves, I., R. Pokorny, M. Byrdin, N. Hoang, T. Ritz, K. Rettel, L.-O. Essen, G.T.J. van der Horst, A. Batschauer, and M. Ahmad. 2011. The cryptochromes: Blue light photoreceptors in plants and animals. Annu. Rev. Plant Biol. 62:335-364.

Favory, J.-J., A. Stec, H. Gruber, L. Rizzini, A. Oraveca, M. Funk, A. Albert, C. Cloix, G.I. Jenkins, E.J. Oakeley, H.K. Seidlitz, F. Nagy, and R. Ulm. 2009. Interaction of COP1 and UVR8 regulates UV-Binduced photomorphogenesis and stress acclimation in Arabidopsis. EMBO J. 28:591-601.

Fortnum, B.A. and M.J. Kasperbauer. 1992. Biomass partitioning and root-knot nematode development in tomato plants under end-of-day red or far-red light. Crop Sci. 32:408-411.

Glenn, D.M., A. Erez, G.J. Puterka, and P. Gundrum. 2003. Particle films affect carbon assimilation and yield in 'Empire' apple. J. Amer. Soc. Hort. Sci. 128:356-362.

Glenn, D.M. and G.J. Puterka. 2007. The use of plastic films and sprayable reflective particle films to increase light penetration in apple canopies and improve apple color and weight. HortScience 42:91-96.

Glenn, D.M., G.J. Puterka, S.R. Drake, T.R. Unruh, A.L. Knight, P. Baherle, E. Prado, and T.A. Baugher. 2001. Particle film application influences apple leaf physiology, fruit yield and fruit quality. J. Amer. Soc. Hort. Sci. 126:175-181.

Gueymard, C. 2004. The sun's total and spectral irradiance for solar energy applications and solar radiation models. Sol. Energy 76:423453.

Harari-Steinberg, O., I. Ohad, and D.A. Chamovitz. 2001. Dissection of the light signal transduction pathways regulating the two early lightinduced protein genes in Arabidopsis. Plant Physiol. 127:986-997.

Hornitschek, P., S. Lorrain, V. Zoete, O. Michielin, and C. Fankhauser. 2009. Inhibition of the shade avoidance response by formation of non-DNA binding bHLH heterodimers. EMBO J. 28:3893-3902.

Huang, X. and A. Madan. 1999. CAP3: A DNA sequence assembly program. Genome Res. 9:868-877.

Hutin, C., L. Nussaume, N. Moise, I. Moya, K. Kloppstech, and M. Havaux. 2003. Early light-induced proteins protect Arabidopsis from photooxidative stress. Proc. Natl. Acad. Sci. USA 100:4921-4926.

Kasperbauer, M.J. 1987. Far-red light reflection from green leaves and effects on phytochrome mediated assimilate partitioning under field conditions. Plant Physiol. 85:350-354.

Kasperbauer, M.J. 2000. Strawberry yield over red versus black plastic mulch. Crop Sci. 40:171-174.

Kasperbauer, M.J. and P.G. Hunt. 1998. Far-red light affects photosynthate allocation and yield of tomato over red mulch. Crop Sci. 38:970-974.

Kasperbauer, M.J. and D.L. Karlen. 1986. Light mediated bioregulation of tillering and photosynthate partitioning in wheat. Physiol. Plant. 66:159-163.
Kim, W.-Y., S. Fujiwara, S.-S. Suh, J. Kim, Y. Kim, L. Han, K. David, J. Putterill, H.G. Nam, and D.E. Somers. 2007. ZEITLUPE is a circadian photoreceptor stabilized by GIGANTEA in blue light. Nature 449:356-360.

Kircher, S., P. Gil, L. Kozma-Bognár, E. Fejes, V. Speth, T. Husselstein-Muller, D. Bauer, E. Ádám, E. Schäfer, and F. Nagy. 2002. Nucleocytoplasmic partitioning of the plant photoreceptors phytochrome A, B, C, D and E is regulated differentially by light and exhibits a diurnal rhythm. Plant Cell 14:1541-1555.

Kircher, S., L. Kozma-Bognar, L. Kim, E. Adam, K. Harter, E. Schäfer, and F. Nagy. 1999. Light quality-dependent nuclear import of the plant photoreceptors phytochrome A and B. Plant Cell 11:1445-1456.

Koornneef, M., E. Rolff, and C.J.P. Spruit. 1980. Genetic control of light-inhibited hypocotyl elongation in Arabidopsis thaliana (L.) Heynh. Zeitschrift fur Pflanzenphysiologie 100:147-160.

Kühn, N., J. Ormeño-Núñez, G. Jaque-Zamora, and F.J. Pérez. 2009. Photoperiod modifies the diurnal expression profile of VvPHYA and VvPHYB transcripts in field-grown grapevine leaves. J. Plant Physiol. 166:1172-1180.

Layne, D.R., Z. Jiang, and J.W. Rushing. 2001. Tree fruit reflective film improves red skin coloration and advances maturity in peach. HortTechnology 11:234-242.

Layne, D.R., Z. Jiang, and J.W. Rushing. 2002. The influence of reflective film and ReTain on red skin coloration and maturity of 'Gala' apples. HortTechnology 12:640-645.

Lee, J., K. He, V. Stolc, H. Lee, P. Figueroa, Y. Gao, W. Tongprasit, H. Zhao, I. Lee, and X.W. Deng. 2007. Analysis of transcription factor HY5 genomic binding sites revealed its hierarchical role in light regulation of development. Plant Cell 19:731-749.

Leivar, P., E. Monte, B. Al-Sady, C. Carle, A. Storer, J.M. Alonso, J.R. Ecker, and P.H. Quail. 2008. The Arabidopsis phytochrome-interacting factor PIF7, together with PIF3 and PIF4, regulates responses to prolonged red light by modulating phyB levels. Plant Cell 20:337-352.

Liu, B., Z. Zuo, H. Liu, X. Liu, and C. Lin. 2011. Arabidopsis cryptochrome 1 interacts with SPA1 to suppress COP1 activity in response to blue light. Genes Dev. 25:1029-1034.

Lorrain, S., T. Allen, P.D. Duek, G.C. Whitelam, and C. Fankhauser. 2008. Phytochrome-mediated inhibition of shade avoidance involves degradation of growth-promoting bHLH transcription factor. Plant J. 53:312-323

Lu, C., O.A. Koroleva, J.F. Farrar, J. Gallagher, C.J. Pollock, and A.D. Tomos. 2002. Rubisco small subunit, chlorophyll $a / b$-binding protein and sucrose:fructan-6-fructosyl transferase gene expression and sugar status in single barley leaf cells in situ. Cell type specificity and induction by light. Plant Physiol. 130:1335-1348.

Madlung, A., R.W. Masuelli, B. Watson, S.H. Reynolds, J. Davison, and L. Comai. 2002. Remodeling of DNA methylation and phenotypic and transcriptional changes in synthetic Arabidopsis allotetraploids. Plant Physiol. 129:733-746.

Marini, R.P. and J.A. Barden. 1987. Summer pruning of apple and peach trees. Hort. Rev. 9:351-376.

Matheny, T.A., P.G. Hunt, and M.J. Kasperbauer. 1992. Potato tuber production in response to reflected light from different colored mulches. Crop Sci. 32:1021-1024.

Miller, S.S. and G.M. Greene, II. 2003. The use of reflective film and ethephon to improve red skin color of apples in the mid-Atlantic region of the United States. HortTechnology 13:90-99.

Mishra, Y., H.J. Jänkänpää, A.Z. Kiss, C. Funk, W.P. Schröder, and S. Jansson. 2012. Arabidopsis plants grown in the field and climate chambers significantly differ in leaf morphology and photosystem components. BMC Plant Biol. doi:10.1186/1471-2229-12-6.

Mockler, T.C., H. Yang, X. Yu, D. Parikh, Y. Cheng, S. Dolan, and C. Lin. 2003. Regulation of photoperiodic flowering by Arabidopsis photoreceptors. Proc. Natl. Acad. Sci. USA 100:2140-2145.

Moreshet, S., Y. Cohen, and M. Fuchs. 1979. Effect of increasing foliage reflectance on yield, growth, and physiological behavior of a dry land cotton crop. Crop Sci. 19:863-868. 
Oyama, T., Y. Shimura, and K. Okada. 1997. The Arabidopsis HY5 gene encodes a bZIP protein that regulates stimulus-induced development of root and hypocotyls. Genes Dev. 11:2983-2994.

Rizzini, L., J.-J. Favory, C. Cloix, D. Faggionato, A. O'Hara, E. Kaiserli, R. Baumeister, E. Schafer, F. Nagy, G.I. Jenkins, and R. Ulm. 2011. Perception of UV-B by the Arabidopsis UVR8 protein. Science 332:103-106.

Roig-Villanova, I., J. Bou, C. Sorin, P.F. Devlin, and J.F. MartinezGarcia. 2006. Identification of primary target genes of phytochrome signaling. Early transcriptional control during shade avoidance responses in Arabidopsis. Plant Physiol. 141:85-96.

Rozen, S. and H.J. Skaletsky. 1998. Primer3. 18 Apr. 2014. <http:// biotools.umassmed.edu/bioapps/primer3_www.cgi>.

Sakamoto, K. and A. Nagatani. 1996. Nuclear localization activity of phytochrome B. Plant J. 10:859-868.

Salter, M.G., K.A. Franklin, and G.C. Whitelam. 2003. Gating of the rapid shade-avoidance response by the circadian clock in plants. Nature 426:680-683.

Sanzol, J. 2010. Dating and functional characterization of duplicated genes in the apple (Malus domestica Borkh.) by analyzing EST data. BMC Plant Biol. 10:87.

Sellaro, R., M.J. Yanovsky, and J.J. Casal. 2011. Repression of shadeavoidance reactions by sunfleck induction of HY5 expression in Arabidopsis. Plant J. 68:919-928.

Stanhill, G., S. Moreshet, and M. Fuchs. 1976. Effect of increasing foliage and soil reflectivity on the yield and water use efficiency of grain sorghum. Agron. J. 68:329-332.

Tokutomi, S., D. Matsuoka, and K. Zikihara. 2008. Molecular structure and regulation of phototropin kinase by blue light. Biochim. Biophys. Acta. Proteins Proteomics 1784:133-142.

Ulm, R., A. Baumann, A. Oravecz, Z. Máté, E. Ádám, E.J. Oakeley, E. Schäfer, and F. Nagy. 2004. Genome-wide analysis of gene expression reveals function of the bZIP transcription factor HY5 in the UVB response of Arabidopsis. Proc. Natl. Acad. Sci. USA 101:13971402 .
Untergasser, A., H. Nijveen, X. Rao, T. Bisseling, R. Geurts, and J.A.M. Leunissen. 2007. Primer3Plus, an enhanced web interface to Primer3. Nucleic Acids Res. 35:W71-W74.

Vandenbussche, F., Y. Habricot, A.S. Condiff, R. Maldiney, D. Van Der Straeten, and M. Ahmad. 2007. HY5 is a point of convergence between cryptochrome and cytokinin signalling pathways in Arabidopsis thaliana. Plant J. 49:428-441.

Velasco, R., A. Zharkikh, J. Affourtit, A. Dhingra, A. Cestaro, A. Kalyanaraman, P. Fontana, S.K. Bhatnagar, M. Troggio, D. Pruss, S. Salvi, M. Pindo, P. Baldi, S. Castelletti, M. Cavaiuolo, G. Coppola, F. Costa, V. Cova, A.D. Ri, V. Goremykin, M. Komjanc, S. Longhi, P. Magnago, G. Malacarne, M. Malnoy, D. Micheletti, M. Moretto, M. Perazzolli, A. Si-Ammour, S. Vezzulli, E. Zini, G. Eldredge, L.M. Fitzgerald, N. Gutin, J. Lanchbury, T. Macalma, J.T. Mitchell, J. Reid, B. Wardell, C. Kodira, Z. Chen, B. Desany, F. Niazi, M. Palmer, T. Koepke, D. Jiwan, S. Schaeffer, V. Krishnan, C. Wu, V.T. Chu, S.T. King, J. Vick, Q. Tao, A. Mraz, A. Stormo, K. Stormo, R. Bogden, D. Ederle, A. Stella, A. Vecchietti, M.M. Kater, S. Masiero, P. Lasserre, Y. Lespinasse, A.C. Allan, V. Bus, D. Chagné, R.N. Crowhurst, A.P. Gleave, E. Lavezzo, J.A. Fawcett, S. Proost, P. Rouzé, L. Sterck, S. Toppo, B. Lazzari, R.P. Hellens, C.-E. Durel, A. Gutin, R.E. Bumgarner, S.E. Gardiner, M. Skolnick, M. Egholm, Y. Van de Peer, F. Salamini, and R Viola. 2010. The genome of the domesticated apple (Malus domestica Borkh.). Nat. Genet. 42:833-839.

Wargent, J.J. and B.R. Jordan. 2013. From ozone depletion to agriculture: Understanding the role of UV radiation in sustainable crop production. New Phytol. 197:1058-1076.

Watari, J., Y. Kobae, S. Yamaki, K. Yamada, K. Toyofuku, T. Tabuchi, and K. Siratake. 2004. Identification of sorbitol transporters expressed in the phloem of apple source leaves. Plant Cell Physiol. 45:1032-1041.

Wisniewski, M., C. Bassett, J. Norelli, D. Macarisin, T. Artlip, K. Gasic, and S. Korban. 2008. Expressed sequence tag analysis of the response of apple (Malus $\times$ domestica 'Royal Gala') to low temperature and water deficit. Physiol. Plant. 133:298-317. 
Supplemental Table 1. Comparison of apple genes to Arabidopsis thaliana, barrel medic, Medicago truncatula Gaertn., and grape, Vitis vinifera L., genes.

\begin{tabular}{|c|c|c|c|c|}
\hline Locus tag & Gene & Source & E value & Total score \\
\hline MDP0000290263 & & BLAST match apple, chr12 & $-^{z}$ & - \\
\hline At2g46970 & Pill & Arabidopsis thaliana & $7 e-42$ & 187 \\
\hline At3g62090 & Pil2 & Arabidopsis thaliana & $7 e-28$ & 182 \\
\hline At1g09530 & Pif3 & Arabidopsis thaliana & $3 e-78$ & 251 \\
\hline MTR1g084980 & Pif3 & Medicago truncatula & $<1 \mathrm{e}-179$ & 532 \\
\hline MDP0000205358 & & BLAST match apple, chr4 & - & - \\
\hline MDP0000290263 & & BLAST match apple, chr12 & $<1 \mathrm{e}-179$ & 1135 \\
\hline At2g46970 & Pill & Arabidopsis thaliana & $1 e-39$ & 197 \\
\hline At3g62090 & Pil2 & Arabidopsis thaliana & $7 e-25$ & 170 \\
\hline At1g09530 & Pif3 & Arabidopsis thaliana & $5 e-76$ & 245 \\
\hline MTR1g084980 & Pif3 & Medicago truncatula & $<1 \mathrm{e}-179$ & 540 \\
\hline MDP0000896307 & MdSOT3 & BLAST match apple, chr12 & - & - \\
\hline At2g16120 & Pmt1 & Arabidopsis thaliana & $<1 \mathrm{e}-179$ & 676 \\
\hline MDP0000264514 & MdHy5 & BLAST match apple genome, chr12 & - & - \\
\hline MDP0000586302 & MdHy5 & BLAST match apple genome, chr12 & $5 e-115$ & 317 \\
\hline AT5g11260 & Hy5 & Arabidopsis thaliana & $2 \mathrm{e}-68$ & 199 \\
\hline AGN75071 & Hy 5 & Vitis vinifera & $5 e-77$ & 221 \\
\hline MDP0000586302 & MdHy5 & BLAST match apple genome, chr12 & - & - \\
\hline At5g11260 & Hy5 & Arabidopsis thaliana & $2 \mathrm{e}-71$ & 203 \\
\hline AGN75071 & Hy 5 & Vitis vinifera & $2 \mathrm{e}-78$ & 221 \\
\hline MDP0000840536 & MdElip1A & BLAST match apple genome, chr9 & - & - \\
\hline MDP0000542944 & MdElip $1 B$ & BLAST match apple genome, chr16 & $1 \mathrm{e}-121$ & 334 \\
\hline At3g22840 & AtLil1 & Arabidopsis thaliana & $9 \mathrm{e}-70$ & 201 \\
\hline At4g14690 & AtLil2 & Arabidopsis thaliana & $5 e-65$ & 189 \\
\hline MDP0000542944 & MdElip $1 B$ & BLAST match apple genome, chr16 & - & - \\
\hline At3g22840 & AtLill & Arabidopsis thaliana & $2 \mathrm{e}-70$ & 203 \\
\hline At4g14690 & AtLil2 & Arabidopsis thaliana & $4 e-64$ & 187 \\
\hline MDP0000872569 & MdElip $1 D$ & BLAST match apple genome, chr14 & - & - \\
\hline MDP0000840536 & MdElip1A & & $9 e-75$ & 214 \\
\hline MDP0000542944 & MdElip1B & & $1 \mathrm{e}-74$ & 241 \\
\hline At3g22840 & AtLill & Arabidopsis thaliana & $5 e-55$ & 189 \\
\hline At4g14690 & AtLil2 & Arabidopsis thaliana & $1 e-52$ & 181 \\
\hline MDP0000774288 & $M d A c t 1^{\mathrm{y}}$ & BLAST match apple genome, chr13 & - & - \\
\hline At2g37620 & AtActl & Arabidopsis thaliana & $<\mathrm{e}-179$ & 759 \\
\hline At3g18789 & AtAct2 & Arabidopsis thaliana & $<\mathrm{e}-179$ & 706 \\
\hline At3g53750 & AtAct3 & Arabidopsis thaliana & $<\mathrm{e}-179$ & 759 \\
\hline At5g59370 & AtAct 4 & Arabidopsis thaliana & $<\mathrm{e}-179$ & 749 \\
\hline At5g09810 & AtAct7 & Arabidopsis thaliana & $<\mathrm{e}-179$ & 774 \\
\hline At1g49240 & AtAct8 & Arabidopsis thaliana & $<\mathrm{e}-179$ & 747 \\
\hline At2g42090 & AtAct9 & Arabidopsis thaliana & $<\mathrm{e}-179$ & 566 \\
\hline At3g46520 & AtAct 12 & Arabidopsis thaliana & $<\mathrm{e}-179$ & 751 \\
\hline MDP0000572047 & MdAct2 & BLAST match apple genome, chr1 & - & - \\
\hline MDP0000774288 & MdAct1 & BLAST match apple genome, chr13 & $<\mathrm{e}-179$ & 776 \\
\hline At2g37620 & AtAct1 & Arabidopsis thaliana & $<\mathrm{e}-179$ & 759 \\
\hline At3g18789 & AtAct2 & Arabidopsis thaliana & $<\mathrm{e}-179$ & 701 \\
\hline At3g53750 & AtAct3 & Arabidopsis thaliana & $<\mathrm{e}-179$ & 759 \\
\hline At5g59370 & AtAct 4 & Arabidopsis thaliana & $<\mathrm{e}-179$ & 748 \\
\hline At5g09810 & AtAct 7 & Arabidopsis thaliana & $<\mathrm{e}-179$ & 772 \\
\hline At1g49240 & AtAct8 & Arabidopsis thaliana & $<\mathrm{e}-179$ & 741 \\
\hline
\end{tabular}

Continued next page 
Supplemental Table 1. Continued.

\begin{tabular}{|c|c|c|c|c|}
\hline Locus tag & Gene & Source & E value & Total score \\
\hline At2g42090 & AtAct9 & Arabidopsis thaliana & $<\mathrm{e}-179$ & 563 \\
\hline At3g46520 & AtAct12 & Arabidopsis thaliana & $<\mathrm{e}-179$ & 749 \\
\hline MDP0000316929 & $M d R b c S$ & BLAST match apple genome, chr13 & - & - \\
\hline AT5g38430 & $A t R b c S 1 B$ & & $2 \mathrm{e}-44$ & 174 \\
\hline AT5g38420 & $A t R b c S 2 B$ & & $6 e-44$ & 190 \\
\hline MDP0000181339 & $M d R b c S$ & BLAST match apple genome, chr13 & - & - \\
\hline MDP0000316929 & $M d R b c S$ & & $<\mathrm{e}-179$ & 1157 \\
\hline AT5g38430 & $A t R b c S 1 B$ & Arabidopsis thaliana & $1 e-61$ & 223 \\
\hline AT5g38420 & $A t R b c S 2 B$ & Arabidopsis thaliana & $2 e-61$ & 239 \\
\hline AT5g38410 & $A t R b c S 3 B$ & Arabidopsis thaliana & $4 e-61$ & 223 \\
\hline MDP0000285110 & $M d P h y B$ & BLAST match apple genome, chr16 & - & - \\
\hline At2g18790 & $A t P h y B$ & & $<\mathrm{e}-179$ & 1859 \\
\hline At4g16250 & AtPhyD & & $<\mathrm{e}-179$ & 1752 \\
\hline
\end{tabular}

$z_{-}=\mathrm{E}$ value and Total score are perfect match to self.

${ }^{\mathrm{y}} \mathrm{MDP} 0000304059$ on chr7 (not shown) was a match to the other two apple actins, but there were seven mismatched nucleotides (seven of $24=$ $30 \%$ ) in the MdActF1 primer, making it unlikely that RNA from this locus would be detected with reverse transcription-polymerase chain reaction.

${ }^{x}$ Sanzol (2010). 
Supplemental Table 2. Primers used in RT-PCR reactions.

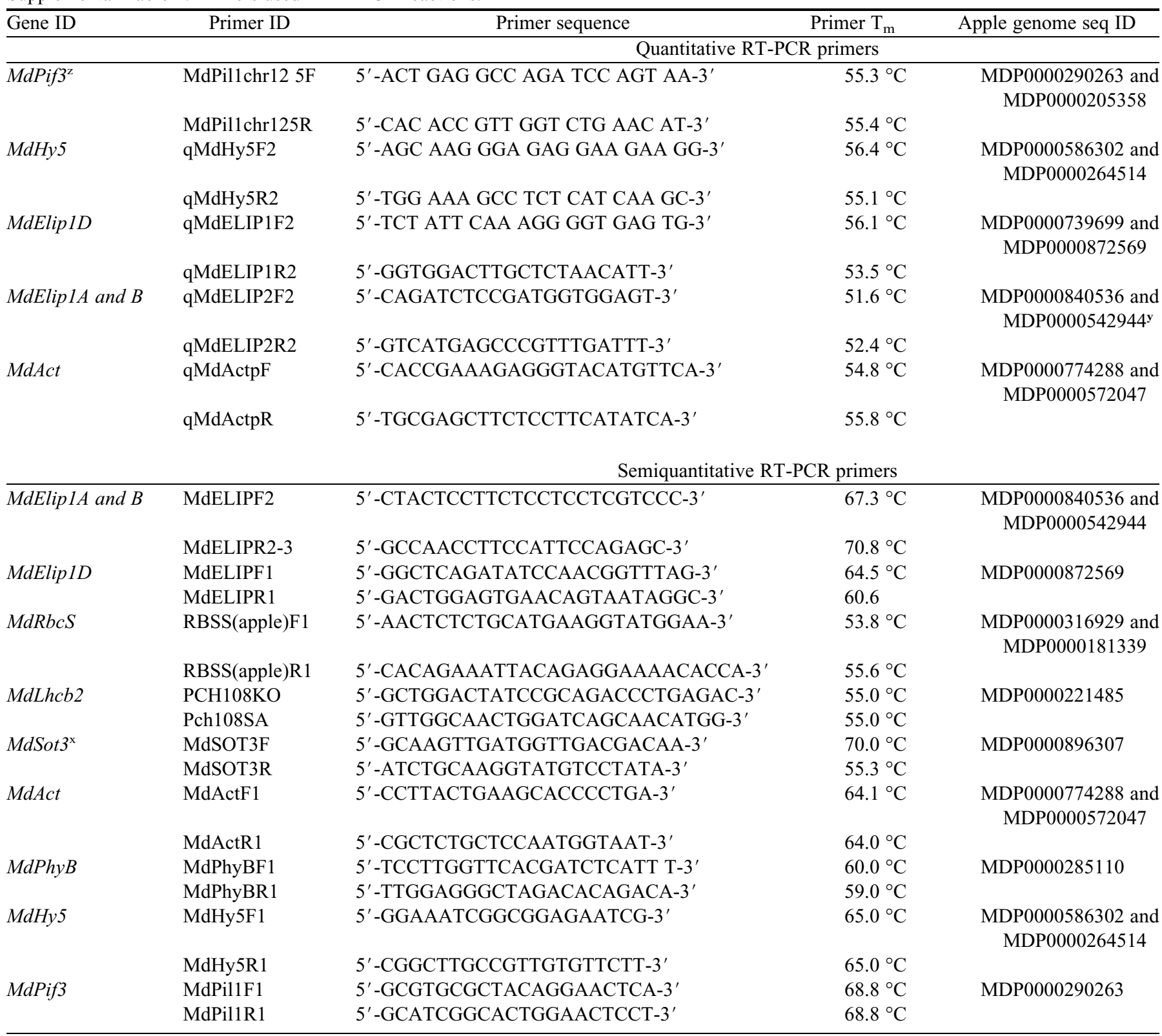

${ }^{\mathrm{z}}$ There are two nearly identical Pif3 genes in the apple genome: one on chr12 and one on chr4. Primer pair is specific for Pif3 on chr12 but may also hybridize to a lesser degree with transcripts from Pif3 on chr4.

${ }^{y}$ Two nearly identical genes match the forward and reverse primers. MDP0000840536 is a perfect match but MDP0000542944 is mismatched by two nucleotides in both primer pairs.

${ }^{x}$ Because the melting temperatures of the primer pair for this gene differ significantly, initial RT-PCR reactions were run in a gradient thermocycler to optimize the annealing temperature $\left(59^{\circ} \mathrm{C}\right)$ for subsequent semiquantitative RT-PCR reactions.

$\mathrm{RT}-\mathrm{PCR}=$ reverse transcription-polymerase chain reaction. 


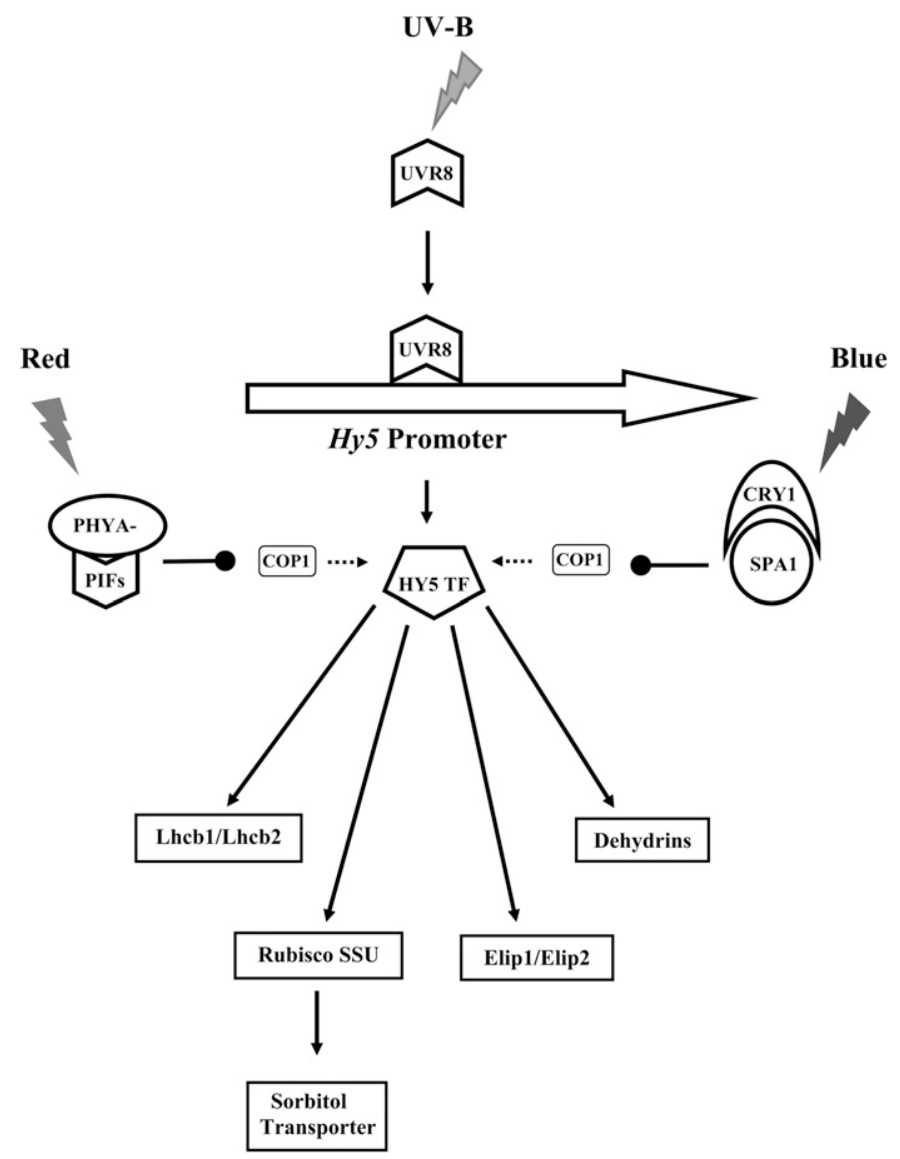

Supplemental Fig. 1. Light regulation through HY5. HY5 acts as a central regulator in light signaling pathways driven by red, blue/UV-A, and UV-B. COP1, an E3 ligase, targets HY5 for degradation in the dark. Under red or blue light, complexes formed between PHYA-E and PIFs (red) or CRY1 and SPA1 (blue/UV-A) prevent the degradation of HY5 and allow the activation of its target genes. UV-B light is perceived by the UVR8 receptor, which can bind directly to HY5 to promote its transcription. Although UVR8 also binds COP1, it is not clear whether this activity contributes to HY5 activation by preventing its degradation. UV = ultraviolet. 


\section{Shade Avoidance}

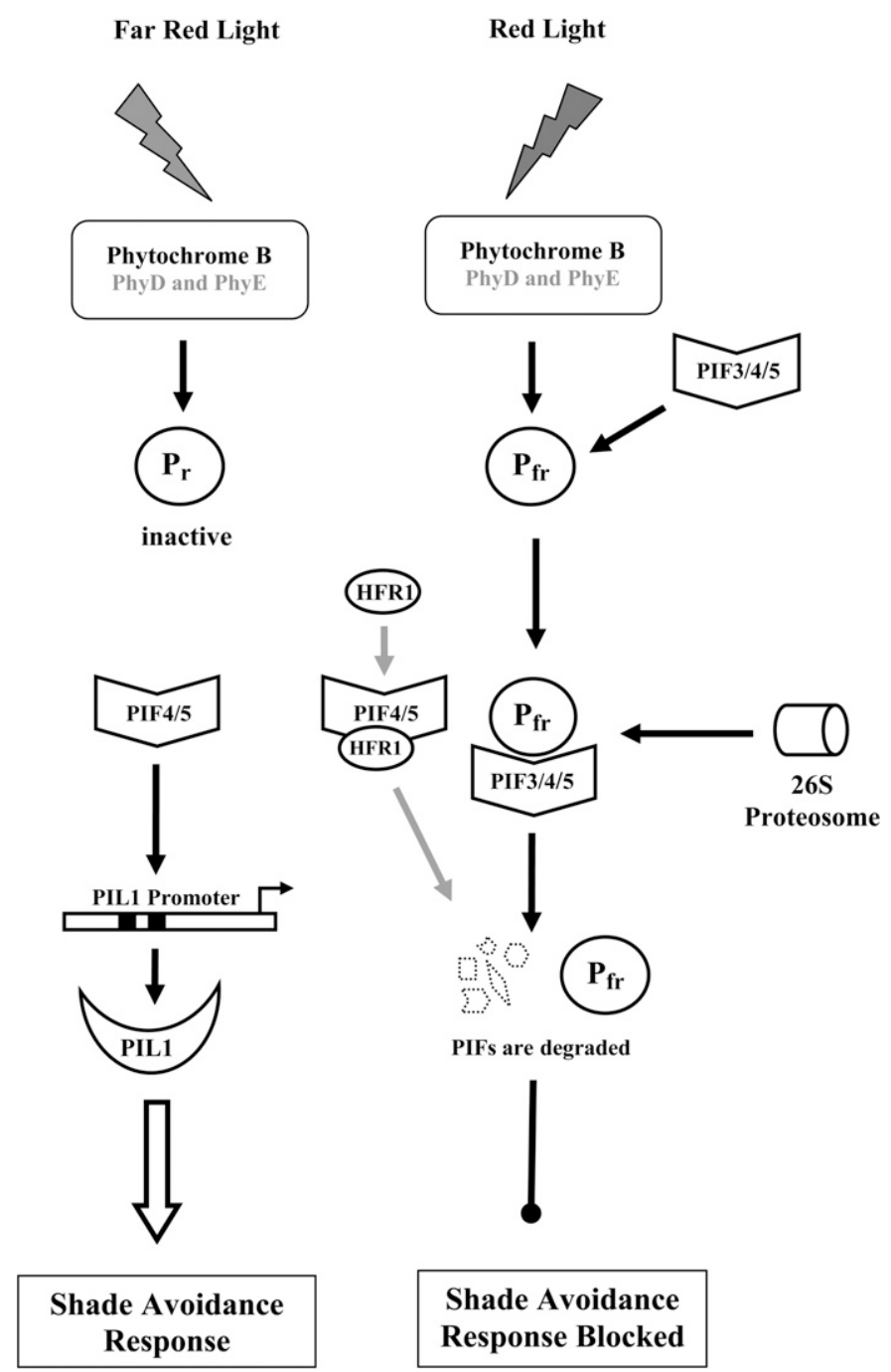

Supplemental Fig. 2. Shade avoidance mechanisms. Under the far-red light, PHYb is in its inactive form and the PIF transcription factors are free to transcribe PIL1 and other genes to activate the shade avoidance response. Under red (PIF4/5) and prolonged red light (PIF3/7), the PIF transcription factors bind to the active (Pfr) form of PHYB (Leivar et al., 2008). The PHYB:PIF complex facilitates degradation of the PIFs by the 26S proteosome, thus preventing activation of PIL 1 by the PIF transcription factors and causing the shade avoidance response to be blocked. An alternative pathway involves the binding of HFR1 (long hypocotyl in far-red light) to the PIF factors (Hornitschek et al., 2009; Lorrain et al., 2008). This complex also favors degradation of the PIFs and blocks the shade avoidance response. No direct interaction with PHYB is proposed. 


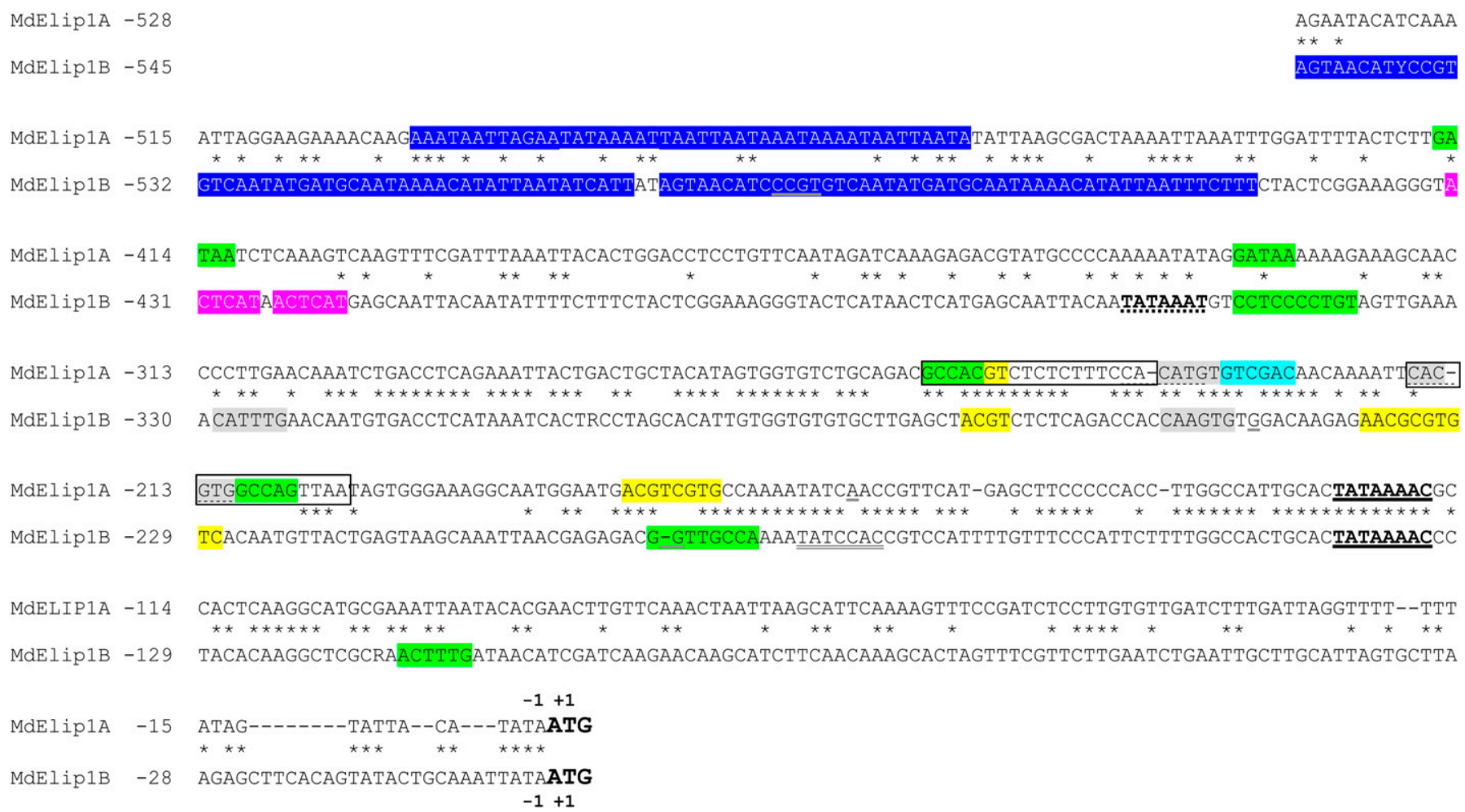

Supplemental Fig. 3. Promoter comparison of MdElip1A and IB. Promoters (approximately $1000 \mathrm{bp}$ upstream of the translation start site (bold) were analyzed by PLACE and Plant CARE. Bases identical to both promoters are indicated by asterisks. Consensus TATA boxes are bold-underlined; an upstream consensus TATA box is bold-dotted underlined. Relevant cis-acting elements on the plus strand are indicated as follows: green highlight = light regulation, different binding sites $[\mathrm{GCCAC} / \mathrm{G}, \mathrm{ACGT}, \mathrm{GATA}]$ collectively boxed = PIF3 element; yellow highlight = putative hormone (e.g., ABA) and light response element core (note that two of the Pif3 elements have an ACGT core); gray highlight = Myb/Myc element (CANNTG consensus) (note that these elements overlap two of the Pif3 elements); dark blue highlight $=$ tandem repeat of unknown function; light blue highlight $=$ low temperature/CBF element (note that in $M d E l i p 1 A$, it has been altered); magenta highlight $=$ osmoregulatory element. $\mathrm{R}=\mathrm{A}$ or $\mathrm{G} ; \mathrm{Y}=\mathrm{C}$ or T. The TATCCAC box (double underlined in MdElip 1B but altered in MdElip1A) is associated with GA response and requires the GA response element (upstream of illustration) and a pyrimidine box (CCTTT and TTTTTTCC) also upstream of illustration. MdElip1A has two heat shock elements much further upstream of the consensus TATA box; MdElip1B has a single HSE in a similar position in the promoter (not shown). 